\title{
Effects of Biomass Burning On Carbon Sequestration and Air Quality under Slash-And-Burn Agriculture
}

\author{
Ini D. Edem ${ }^{1}$, Oliver A. Opara-Nadi ${ }^{2}$, Christiana J. Ijah ${ }^{3}$ \\ ${ }^{1}$. Department of Soil Science, University of Uyo, P.M. B.1017, Uyo, Akwa Ibom State,Nigeria. \\ 2. Department of Soil Science, Abia State University P.M.B. 2000 Uturu \\ 3. Department of Soil and Environmental Sciences Akwa Ibom State University, Obio Akpa.
}

\begin{abstract}
Changes in soil properties, soil organic C (SOC) and total nitrogen (TN) stocks associated with different heating temperatures from 50,100 , and $150 \mathrm{~kg} / \mathrm{m}^{2}$ dry biomass that provided for different heat intensities were compared with natural soil temperature of continuous cultivated arable land adjacent to the burnt plots. Soil samples were collected in three replicates from control and burnt plots and soil temperatures were measured with fire resistance soil thermometer placed at surface and sub-surface layers, while gases emission were measured with sensitive gas dictators. The induced temperatures were highly variable at the soil surface whereas below $15 \mathrm{~cm}$ depth, the temperature rise was not more than $37^{\circ} \mathrm{C}$. The passage of fire promoted $\mathrm{SOC}$ and TN stocks, mean weight diameter, the aggregation of $2 \mathrm{~mm}$ stable structures which become even more resistant to disrupting action of water. Air quality measurement revealed that $\mathrm{NO}_{2}, \mathrm{SO}_{2} \mathrm{H}_{2} \mathrm{~S}$ and $\mathrm{CO}_{2}$ were above the Federal Ministry of Environment \& Protection (FME\&P) permissive limits indicating air pollution through these activities.
\end{abstract}

Key words: Slash-and- burn, traditional farming, air quality, modification, temperature

\section{Introduction}

Soil organic matter has recently been implicated as an important sink for atmospheric carbon dioxide. However the relative impacts on various agricultural management practices on soil organic carbon dynamics and therefore, $\mathrm{C}$ sequestration under slash and burn have rarely been reported ${ }^{8}$. Atmospheric concentration of several green house gases (GHGs) has changed drastically since the industrial revolution because of biomass burning and other factors like bush burning and fossil fuel combustion. The concentration of $\mathrm{CO}_{2}$ responsible for $62 \%$ of the total radiative forcing by earth has increased by $35 \%$ from $280 \%$ around 1750 to $377 \%$ in $2006^{9}$. The concentration of methane $\left(\mathrm{CH}_{4}\right)$, responsible for $20 \%$ of the radiative forcing of the earth, has also increased by $155 \%$ from about $700 \mathrm{ppb}$ around 1750 to $1785 \mathrm{ppb}$ in 2004. the atmospheric concentration of nitrous oxide $\left(\mathrm{N}_{2} \mathrm{O}\right)$, responsible for about $6 \%$ of the radiative forcing of the earth has increased by $18 \%$ from about $270 \mathrm{ppb}$ around 1750 to $318.6 \mathrm{ppb}$ in $2004^{7}$. According to Ruddiman ${ }^{5,6}$, soil cultivation is not as obvious a source of atmospheric $\mathrm{CO}_{2}$ as are fossil fuel combustion, deforestation, and biomass burning. Yet world soils have been a dominant source of $\mathrm{CO}_{2}$ ever since the dawn of settled agriculture ${ }^{7}$.

However with simplification, there are tradeoffs in the form of increase uncertainty, particularly with the application of digital gas dictator. Inherent globally averaged emission factors will be subjected to error when applied to a particular country having conditions different from the global mean ${ }^{3}$. In addition, global defaults for soil processes are likely biased in that most of the data in their derivation are from temperate regions, where the preponderance of the field research has been done. Despite these challenges, a number of countries have successfully implemented soil emission inventories and several others including Nigeria are in the process of joining the crusade of climate change with little or no computational data base tailored to this global circumstance. To facilitate this, a default approach with the advantages of having a reliable simple structure as well as providing default emission measure was develop in continuous arable land of humid tropics of Uyo to detect gases emission during bush burning. This work aimed at assessing the effects of this method of farming on air quality soil organic $\mathrm{C}$ and nitrogen sequestrations at varying heating temperatures.

\section{Materials and methods}

The research was conducted in a continuous cropped arable experimental plots located at the University of Uyo Teaching and Research Farm (UUTRF), Use-Offot, Uyo, Nigeria. Uyo is located between latitudes $40^{\circ}$ $30^{\prime}$ and $5^{0} 3^{\prime} \mathrm{N}$ and longitudes $7^{0} 31^{\prime}$ and $8^{\circ} 20^{\prime} \mathrm{E}$ and altitude $65 \mathrm{~m}$ from the sea level. The area is divided into two distinct seasons, the wet or rainy and dry seasons. The wet or rainy season begins from April and lasts till October. It is characterized by heavy rainfall of about $2500-4000 \mathrm{~mm}$ per annum. The rainfall intensity is very high and there is evidenced of high leaching and erosion associated with slope and rainfall factors in the area ${ }^{2}$. The experiment was established in 2009 with the initial goals of analyzing effect of heating temperatures on soil properties and determining changes in soil characteristics and crop growth that could be associated with yield 
differences. Later in 2010 effort was made to measure the emission of some gases during burning exercise. A plot of land measuring $720 \mathrm{~m}^{2}$ on a slope of $9 \%$ was selected and cleared for the study.

A total of six plots each measuring $40 \times 3 \mathrm{~m}^{2}$ were cleared, pegged, and the trash was left on the ground for two weeks to dry. 50,100 , and $150 \mathrm{~kg} / \mathrm{m}^{2}$ of the dry biomass was measured using measuring scale and was imposed on the respective replicated plots to produce three levels of fire intensities, and progressively fire was set into three out of the six plots.

\subsection{Pre-and-post burnt soil samplings}

Nine mini-profile pits $(50 \mathrm{~cm}$ depth) were dug at the centre of each plot. Bulk soil, core and aggregate samples were collected at two depths of $15 \mathrm{~cm}$ interval before and after passage of fire before mineralization of the $\mathrm{CaCO}_{3}$ in the ash content. The core samples were obtained for saturated hydraulic conductivity and bulk density determinations. The soil samples were secured in a core, and one end of the core was covered with a piece of cheese cloth fastened with a rubber band and properly labeled while the bulk samples collected were secured in properly labeled polythene bags before taken to the University of Uyo Soil Science laboratory for physical, chemical and structural parameters determinations using standard methods and procedures ${ }^{1}$.

\subsection{Performance of experimental fires, thermal results and detection of emitted gases}

The experimental fire with measured dry biomass was performed at the end of August 2010. Winds were calm and air temperature was $\pm 24^{\circ} \mathrm{C}$ and relative humidity $80 \%$. The maximum temperatures reached during the fires were recorded by means of fire resistance soil thermometer, while the gas fluxes were measure with portable sensitive gas dictators (Fig. 1).

\subsection{Experimental design and statistical analysis}

The experiment consist of two treatments (burned and un-burned plots) arranged in a RCBD with three replicates. The data obtained were statistically analyzed for variance (ANOVA), and significant means were compared using Fisher's least significant difference $\left(\mathrm{LSD}_{0.05}\right)$. Paired $\mathrm{t}$-test was used to compare means of the unburnt and burnt plots. For all tests, a threshold of $\mathrm{p}<0.05$ was used to define statistical significance. All statistical analyses were performed using SigmaStat 3.5 and validated using SPSS 17.0. Pearson correlation coefficients were used to assess the degree of relationships among variables. Regression equations were used to assess the temporal changes in SOC \& TNS pools for each soil depth ${ }^{4}$, and temperature differences considering the un-burnt plots as base line or reference point. The rates of SOC stock were calculated by determining the slope of the regression line $(\mathrm{dy} / \mathrm{dx})$ for each depth for the 50,100 and $150 \mathrm{~kg} / \mathrm{m}^{2}$ (treatments). Statistical significance was computed at $\mathrm{P} \leq 0.05$ and $\mathrm{P} \leq 0.01$ respectively.

\section{Results and discussion}

\subsection{Thermal effect on soil organic carbon stock (SOCS) and total nitrogen stock (TNS).}

As shown in Fig 3 (a), no significant ( $p>0.05$ ) change in soil organic carbon stock between the surface and sub-surface layers, but soil organic carbon stock was significantly $(p<0.05)$ higher at heating temperature between $25-47^{\circ} \mathrm{C}$ in surface layer than sub-surface soil. Soil organic carbon stock was completely removed from the sub-surface when the soil heating temperature increased up to $48-60^{\circ} \mathrm{C}$. Figure $3(\mathrm{~b})$ showed varied total nitrogen stocks (TNS) at different temperature. Control plot showed no significant $(p>0.05)$ different between total nitrogen stocks in the surface and sub-surface layers. More total nitrogen content was observed on heating the soil, and the surface soil recorded significant high $(p<0.05)$ total nitrogen stocks than the sub-surface soil, but none was found in the sub-surface layer when the temperature increased beyond $37^{0} \mathrm{C}$.

\subsection{Relationships between soil properties and soil carbon stock}

Step wise elimination techniques of pedotranfer function (PTF) were performed to determine the soil properties that are capable of predicting $(p<0.05)$ soil carbon storage in the soil under the two treatments. The model results (Table 1) showed that all properties of the soil in the un-burnt plots were removed except total nitrogen storage (TNS), carbon/nitrogen ratio (C:N), electrical conductively (EC) and exchange acidity (EA), that were retained in the model $(p<0.05)$. The result indicated a positive relationship between soil carbon stock with TNS, C to $\mathrm{N}$ ratio, $\mathrm{EC}$, and EA $(\mathrm{R}=0.951,0.985,0.994$ and 0.996 respectively). The result in the burnt plots showed that, of all the soil properties, total nitrogen $(\mathrm{TN})$, saturated hydraulic conductivity $\left(\mathrm{K}_{\mathrm{s}}\right)$, Organic carbon $(\mathrm{OC})$ and clay were the only properties that significantly $(P<0.05)$ affected SOCS. The excluded soil parameters in the PTF reduced their significance $(p>0.05)$ in determining soil carbon storage after burning. As $\mathrm{TN}, \mathrm{K}_{\mathrm{s}}$ and $\mathrm{OC}$ increase, soil carbon storage also increases with the following significant coefficient of determination ( $R=0.892,0.414$ and 0.769 respectively), but clay had a negative relationship with SCS $(\mathrm{R}=-$ 0.141). That is, soil carbon stock will increase at a reduce clay content. Thus the parameters capable of predicting soil carbon storage before burning is different from those that predicts soil carbon storage after burning. 


\subsection{Relationship of total nitrogen stock with soil properties.}

In order to determine soil properties capable of affecting the storage of total nitrogen in the soil, The PTF result (Table 1) revealed that total nitrogen storage can increase by increasing soil organic carbon storage, carbon to nitrogen ratio, electrical conductivity and exchange acidity with determinant coefficients of 0.943 , 0.981.0.992 and 0.996 respectively. The result further showed that all soil parameters in the burnt plats were removed except total nitrogen and saturated hydraulic conductivity $\left(\mathrm{K}_{\mathrm{s}}\right)$, where a positive significant $(p<0.050)$ relationship was observed with total nitrogen $(\mathrm{R}=0.896)$ whereas, a reduction in $\mathrm{K}_{\mathrm{s}}$ significantly $(P<0.05)$ increase the concentration of total nitrogen stock in the soil $(\mathrm{R}=-0.466)$. Therefore, the role of total nitrogen is very important in the concentration of soil organic carbon and total nitrogen stock in arable farm land.

\subsection{Some emitted gases during the passage of fire at different heating intensities}

As indicated in (Table 2), the measurable gases emitted during experimental fire were $\mathrm{NO}_{2}, \mathrm{SO}_{2} \mathrm{CO}$, $\mathrm{H}_{2} \mathrm{~S}, \mathrm{Cl}_{2}, \mathrm{NH}_{3}$ and $\mathrm{HCN}$. The fluxes of $\mathrm{NO}_{2}$ and $\mathrm{SO}_{2}$ were the same at different heat concentration but other gasses varied. At $50 \mathrm{~kg}$ of biomass per square meter, the respective volume of gases emitted was $0.2,0.2$, and $23.7,0.3,0.5,2.3,0.7 \mathrm{mg} / \mathrm{m}^{2}$ ground space. But for $100 \mathrm{~kg}$ of biomass, $0.2,0.2,26.7,0.4,0.5,3.0$ and 1.0 $\mathrm{mg} / \mathrm{m}^{2}$ were emitted. While for $150 \mathrm{~kg}$ of biomass per square meter, the volume of gases emitted was $0.3,0.2$ 28.0, 0.4, $0.6,3.3$ and $1.0 \mathrm{mg} / \mathrm{m}^{2}$ for $\mathrm{NO}_{2}, \mathrm{SO}_{2}, \mathrm{CO}, \mathrm{H}_{2} \mathrm{~S}, \mathrm{Cl}_{2} \mathrm{NH}_{3}$ and $\mathrm{HCN}$ respectively. The value for these gases was above the permissive limits, indicating air pollution through these activities. Therefore despite the merits of quick release of occluded nutrients during burning, heating temperatures of slash-and-burn method of land clearing altered soil properties and air quality, and these alterations have bearing on the of sustainability of nutrients in the soil, also when the emitted gases $\left(\mathrm{SO}_{2}\right.$ and $\left.\mathrm{H}_{2} \mathrm{~S}\right)$ reacts with water vapour it results in acid rain formation that increased soil acidity. Also, as shown in Fig. 2, the catalytic destruction of ozone by this nitric oxide results in global warming when highly reactive mono-molecular oxygen is struck by ultra violet light and the prevented dangerous UV light rays reaches the earth surface.

Generally, regardless of the quantity of biomass per square meter soil, $\mathrm{CO}$ was the most emitted gas while $\mathrm{SO}_{2}$ was the least emitted during burning exercise. Soils in Uyo, Southern Nigeria exhibit marked differences in physical characteristics under slash and burn land use. These significant changes in soil properties in the upper $15 \mathrm{~cm}$ layer in the burnt plot compared with the sub-soil of the burnt plots and both layers of preburnt soil could be attributed to heating temperature and soil disturbances.

\subsection{Correlation of heating temperatures, depth, SOC and TN stocks with soil properties}

As summarized in Table 3, the correlation of heating temperatures and depths with soil properties in the pre-burnt and burnt plots of arable field revealed that, clay, $1 \mathrm{~mm}, 0.5 \mathrm{~mm}$ stable aggregate and organic carbon relates positively and highly significant $(P<0.05)$ with depth in the burnt plots $\left(\mathrm{r}=0.648 * *, 0.718^{* *}\right.$, $0.712^{* *}, 0.840^{*}$ respectively). This implies that these parameters increase with corresponding increase in depth. But total nitrogen stock, sand, saturated hydraulic conductivity, total nitrogen, soil carbon stock, $\mathrm{pH}$ and electrical conductivity correlated negatively and highly significant with soil depth $\left(\mathrm{r}=-0.617^{* *}\right.$. $-0.656^{* *}$. $0.478^{*},-0.753^{* *},-0.697 * *,-0.835^{* *},-0.544^{*}$ respectively). Therefore, increase in soil depth decreased the concentration of these soil parameters (acidity increases) under burnt condition.

Temperature differences affect sand, total nitrogen, organic carbon and $\mathrm{pH}$ contents of the soils positively $(\mathrm{r}=$ $0.518 * 0.478 * 0.582 * 0.595 *$ respectively), whereas a reduction in the soil temperature increased the concentrations of clay, $1 \mathrm{~mm}, 0.05 \mathrm{~mm}$ and $0.25 \mathrm{~mm}$ stable soil aggregates in the soil $\left(\mathrm{r}=-0.619^{* *},-0.578^{*}\right.$, $0.780,-0.526 *$ respectively) after burning.

Under pre-burnt condition, depth correlates positively and significantly with clay, bulk density, $1 \mathrm{~mm}$ and $0.5 \mathrm{~mm}$ stable soil aggregates to water $\left(\mathrm{r}=0.481^{*}, 0.636^{* *}, 0.773^{*}\right.$ and $0.820^{* *}$ respectively). This means that as the soil depth increase, clay, bulk density, $1 \mathrm{~mm}$ and $0.5 \mathrm{~mm}$ water stable aggregate also increases. As expected, sand saturated hydraulic conductivity and total porosity decreased with an increase in depth $(\mathrm{r}=-$ $0.542^{*}, 0.673^{* *}$,and $-0.643^{* *}$ respectively) in the un-burnt plots. This shows that increase in soil depth decrease sand fraction, $K_{\mathrm{s}}$ and total porosity.

In the burnt plots, soil carbon stocks gave the significant positive correlations with $\mathrm{pH}$, total nitrogen $(\mathrm{TN})$, organic carbon (OC), total nitrogen stock (TNS) and sand $\left(\mathrm{r}=0.581^{*}, 0.892^{* *}, 0.882^{* *} 0.976^{* *}\right.$, and $0.697 * *$ respectively). This means that increase in these soil parameters increased soil carbon storage. But the reverse relationship was true for clay and $1 \mathrm{~mm}$ water stable aggregate $(\mathrm{r}=-0.680 * *$, and $-0.722 * *$ respectively).

\subsection{Changes in soil structural parameter following burning are presented in Table 4}

Mean weight diameter (MWD) significantly $(\mathrm{P}<0.05)$ increased after burning with the mean of $0.46 \mathrm{~mm}$ compared to $0.42 \mathrm{~mm}$ in the unburnt plot. Percent water stable aggregate (WSA) for $1 \mathrm{~mm}, 0.5 \mathrm{~mm}$ and $0.25 \mathrm{~mm}$ sizes decrease but not significant ( $p>0.05$ ) after burning with the mean of $1.58 \%, 1.42 \%$ and $1.86 \%$ respectively compare to $7.63 \%$, and $2.15 \%$ respectively before burning. However, WSA of $2 \mathrm{~mm}$ size increase after burning with the mean of $1.53 \%$ compared to $1.48 \%$.The soil physical disruption in aggregate following 
burning was reflected in reduced aggregate size and concentration of WSA in the soils. The observation in this study agreed with that the findings of many researchers, who found a reduction in aggregate stability following burning $6,7,11,12,13$. However, it was observed in this study that lower value of WSA for $1 \mathrm{~mm}, 0.5 \mathrm{~mm}, 0.25 \mathrm{~mm}$ sizes of soil aggregate after burning were primary due to considerable lower percentage of aggregate present in $1 \mathrm{~mm}, 0.5 \mathrm{~mm}$ and $0.25 \mathrm{~mm}$ diameter size classes. The reduction in clay fraction likely accounted for the reduction in soil WSA, due to the cohesive influence of clays that reduced after burning.

\section{Conclusion}

Fire is a powerful and rapidly acting modifier of the soil environments. Results of this study support the following conclusions: the release of $\mathrm{SO}_{2}$ is not related to the quantity of biomass imposed. $\mathrm{CO}$ and $\mathrm{NH}_{3}$ positively correlated with soil temperature $(p<0.05)$. Potential soil losses, the product of erodibility and erosivity were generally high after clearing and burning. Also Slash-and-burn agriculture alone contributes significantly about $20 \%$ to the annual increase in radiative forcing GHG to trap heat relative to carbondioxide $\left(\mathrm{CO}_{2}\right)$ through emissions of $\mathrm{NO}_{2}, \mathrm{SO}_{2}, \mathrm{CO}, \mathrm{H}_{2} \mathrm{~S}, \mathrm{Cl}_{2}$ and $\mathrm{NH}_{3}$ to a large extent. Based on the foregoing conclusions, one is justified to attribute the problem of erosion in the site to burning and rainfall erosivity. Presently, increased vulnerability of soil to erosion through thermal deformation of secondary particle and there is a complete removal of soil organic $\mathrm{C}$ and $\mathrm{N}$ stocks from the subsurface soil at temperature $>37^{\circ} \mathrm{C}$. Development and promotion of soil management practices that are maximizing $\mathrm{CH}_{3}$ and $\mathrm{CO}_{2}$ sinks while minimizing $\mathrm{NO}_{2}$ and $\mathrm{CO}$ emissions and maintaining crop yields are required to reduce agriculture's contribution to climate change.

\section{Recommendations for future research}

The results of this study indicate the need for a review of the method of land clearing for sustainable agricultural production. Therefore, sequential soil samplings for soil carbon and $\mathrm{N}$ sequestrations should be carried out after slash-and-burn land clearing say, monthly for four growing seasons, to assess further changes in the soil quality attributes

\section{Acknowledgments}

We thank Miss. Ndifreke Etim, an undergraduate student working on Agricultural burning project based at University of Uyo. We thank Mr. Idongesit Ambrose, a staff of Akwa Ibom State Ministry of Environment and BGI-resources LTD. PHC. for access to facilities to complete soil and air quality samples analyses. We acknowledge support from the Department of Soil Science, University of Uyo for providing the experimental site for this study.

\section{References}

[1] Danielson, R. E. and Sutherland, P. L.. Porosity in: Klute, A. (ed) Methods of soil Analysis: Part 1, $2^{\text {nd }}$ (ed.), 1986, Pp. 443-61. Agronomy Monogr. 9. ASA and SSA Madison, WI.

[2] Edem I. Dennis, Uduak C. Udo-Inyang and Ifiok. R. Inim. Erodibility of Slash-and-Burn Soils along a Toposequence in Relation to Four Determinant Soil Characteristics. Journal of Biology, Agriculture and Healthcare. Vol 2, No.5, 2012, PP 93-102

[3] IPCC.. Climate Change 2001: the scientific basis. Inter-Government Panel on climate change. Cambridge Univ. Press, U.K., 2001, P. 867.

[4] Opara-Nadi, O. A.; Uche J. N; Beese F. O and Schuite-Bisping H. Nurient Stocks and C. sequestration in forest and forest-derived land use systems I the rain forest zone of Nigeria. $19^{\text {th }}$ World congress of soil science. Soil solutions for changing world. Brisbane Australia 1-6 August 2010

[5] Ruddiman, W. F. The anthropogenic greenhouse era began thousands of years ago. Clim. Change. 2003, 61: $261-293$.

[6] Ruddiman, W. F. Plows, Plagues, and Petroleum: How Humans took control of climate. Princeton Univ Press, Princeton N.J 2005.

[7] Valzano, I. P ; Greene, R. S. B; Murphy, B. W. Direct effect of Stubble Burning in a direct drill tillage system. Soil Tillage Res. 1997, 142, 209-219.

[8] W.A. Dick, R.L.Blevin, W.W. Frye, S.E. Peter, D.R. Christenson, F.J. Pierce, and M.L.Vitosh. Impacts of agricultural management practices on C sequestration in forest-derived soil of the eastern Corn Belt. Soil \&Tillage Res. 1998, 47, 235-244

WMO. Greenhouse gas Bulletin. The State of Greenhouse Gases in the Atmosphere using Global observations up to December 2004. World Teleological Organization, Geneva, Switzerland. 2006

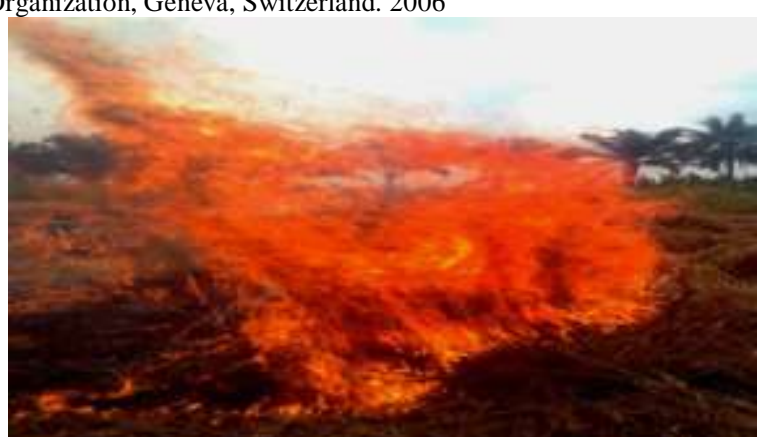

Fig 1: Emission of gases during experimental fire passage on arable land. 


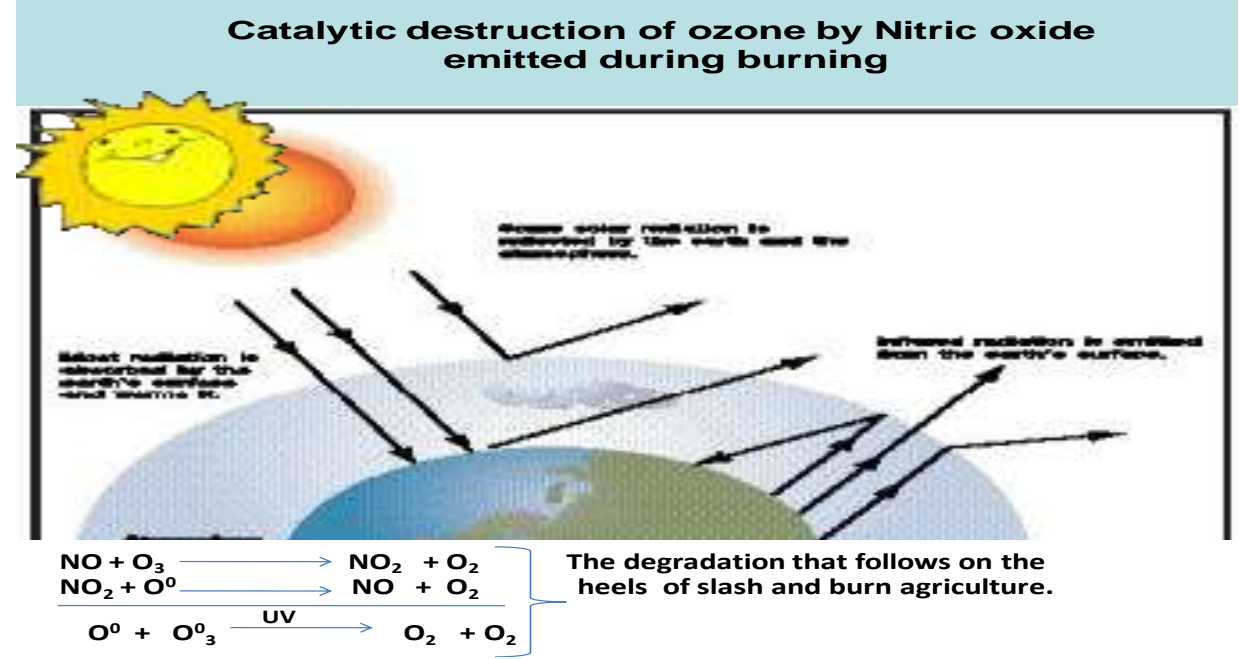

Fig. 2. Ecosystem destruction in photochemically decomposed two-step process of nitrous oxide emitted from burnt soil

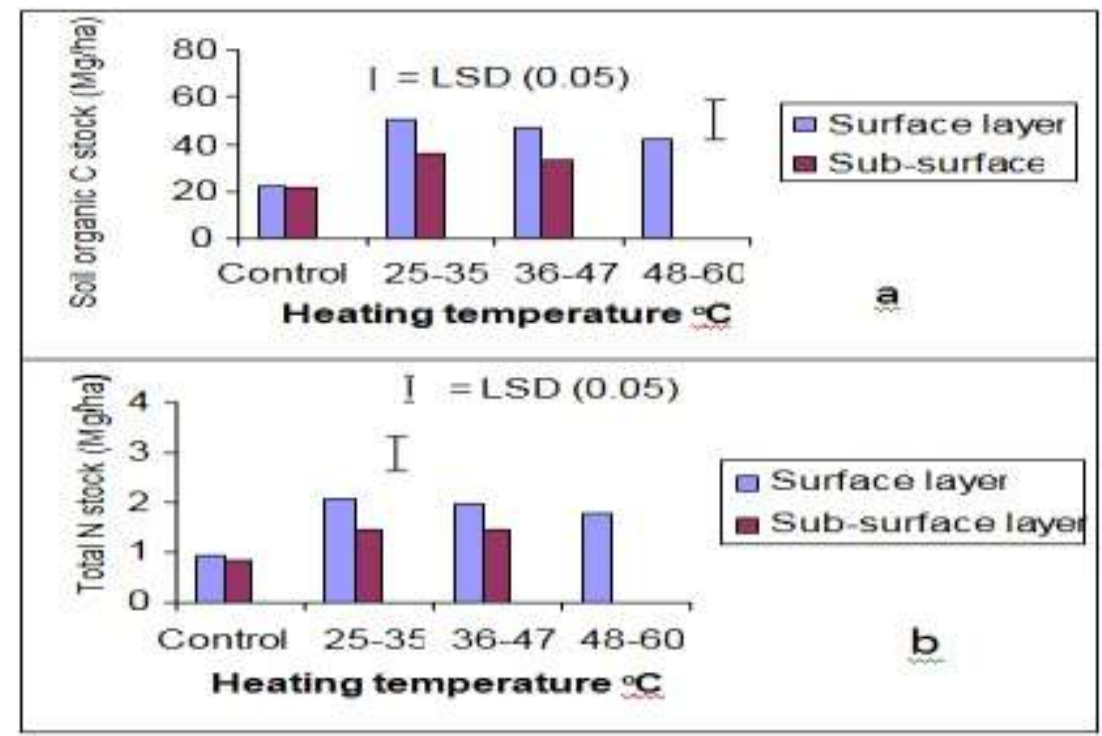

Figure 3 : Soil organic $C$ (a) and $T$ otal $N$ (b) stocks in the surface and sub-surface layers at different heating temperature

Table 1: Relationship between soil carbon (SCS), total nitrogen (TNS) stocks and soil parameters in pre-burnt and post-burnt conditions.

\begin{tabular}{lccl|llll}
\hline Treatments & Parameters & $\mathrm{R}$ & Prob $<0.05$ & & Parameters & $\mathrm{R}$ & Prob $<0.05$ \\
\hline Pre-burnt & TNS & 0.951 & 0.000 & SCS & 0.943 & 0.000 \\
& CN & 0.985 & 0.000 & CN & 0.981 & 0.000 \\
& EC & 0.994 & 0.001 & EC & 0.992 & 0.000 \\
Dependent & EA & 0.996 & 0.024 & EA & 0.996 & 0.024 \\
Variable: SCS & TN & 0.892 & 0.000 & $\begin{array}{l}\text { Dependent } \\
\text { Variable: }\end{array}$ & TN & 0.896 & 0.000 \\
& & & & & & \\
TNS & & KS & -0.466 & 0.000 \\
Post- burnt & KS & 0.414 & 0.000 & & & & \\
& OC & 0.769 & 0.003 & & & & \\
& Clay & -0.141 & 0.039 & & & &
\end{tabular}

Dependent variables: Soil carbon stock (SCS) and Total nitrogen stock (TNS). 
Effects Of Biomass Burning On Carbon Sequestration And Air Quality Under

Table 2: Gases emission (mg/kg) during the experimental burning at different dry biomass content $\left(\mathrm{kg} / \mathrm{m}^{2}\right)$

\begin{tabular}{llllllll}
\hline \multicolumn{7}{c}{ Emitted gases } \\
Biomass & $\mathrm{NO}_{2}$ & $\mathrm{SO}_{2}$ & $\mathrm{CO}$ & $\mathrm{H}_{2} \mathrm{~S}$ & $\mathrm{Cl}_{2}$ & $\mathrm{NH}_{3}$ & $\mathrm{HCN}$ \\
\hline $50 \mathrm{~kg} / \mathrm{m}^{2}$ & 0.2 & 0.2 & 23.7 & 0.3 & 0.5 & 2.3 & 0.7 \\
$100 \mathrm{~kg} / \mathrm{m}^{2}$ & 0.2 & 0.2 & 26.7 & 0.4 & 0.5 & 3.0 & 1.0 \\
$150 \mathrm{~kg} / \mathrm{m}^{2}$ & 0.3 & 0.2 & 28.0 & 0.4 & 0.6 & 3.3 & 1.0 \\
\hline
\end{tabular}

Table 3: Significantly Related Soil Properties with TNS and SCS in the Burnt and Pre-burnt soils .

\begin{tabular}{lll}
\hline Treatments & SCS & TNS \\
& & \\
\hline Post-Burnt & pH $\left(\mathrm{r}=0.581^{*}\right)$ & $\mathrm{pH}\left(\mathrm{r}=0.539^{*}\right)$ \\
& TN $\left(\mathrm{r}=0.892^{* *}\right)$ & TN $\left(\mathrm{r}=0.886^{* *}\right)$ \\
& OC $\left(\mathrm{r}=0.882^{* *}\right)$ & OC $\left(\mathrm{r}=0.831^{* *}\right)$ \\
& TNS $\left(\mathrm{r}=0.976^{* *}\right)$ & SCS $\left(\mathrm{r}=0.976^{* *}\right)$ \\
& Sand $\left(\mathrm{r}=0.697^{* *}\right)$ & Sand $\left(\mathrm{r}=0.665^{* *}\right)$ \\
& Clay $\left(\mathrm{r}=-0.680^{* *}\right)$ & Clay $\left(\mathrm{r}=-0.680^{* *}\right)$ \\
& WSA $\left(\mathrm{r}=-0.722^{* *}\right)$ & WSA $1\left(\mathrm{r}=-0.718^{* *}\right)$ \\
& & \\
Pre burnt & TN $\left(\mathrm{r}=0.765^{* *}\right)$ & TN $\left(\mathrm{r}=0.879^{* *}\right)$ \\
& OC $\left(\mathrm{r}=0.738^{* *}\right)$ & OC $\left(\mathrm{r}=0.794^{* *}\right)$ \\
& TNS $\left(\mathrm{r}=0.943^{* *}\right)$ & SCS $\left(\mathrm{r}=0.943^{* *}\right)$ \\
& Clay $(\mathrm{r}=-0.547 *)$ & Clay $\left(\mathrm{r}=-0.525^{*}\right)$ \\
& MC $\left(\mathrm{r}=-0.714^{*}\right)$ & MC $\left(\mathrm{r}=-0.655^{*}\right)$ \\
\hline
\end{tabular}

** Correlation is significant at the 0.01 level. *Correlation is significant at the 0.05 level.

Table 4: Mean and standard deviation of structural parameters of pre-burnt and post -burnt plots

\begin{tabular}{llll}
\hline Parameters & $\begin{array}{c}\text { Aggregate } \\
\text { sizes }(\mathbf{m m})\end{array}$ & pre-burnt plots & burnt plots \\
\hline WSA \% & 2 & $1.48 \pm 0.43^{\mathrm{a}}$ & $1.53 \pm 0.51^{\mathrm{a}}$ \\
& 1 & $7.63 \pm 3.09^{\mathrm{a}}$ & $1.58 \pm 4.86^{\mathrm{a}}$ \\
& 0.5 & $1.53 \pm 0.47^{\mathrm{a}}$ & $1.42 \pm 0.37^{\mathrm{a}}$ \\
& 0.25 & $2.15 \pm 2.15^{\mathrm{a}}$ & $1.86 \pm 1.13^{\mathrm{a}}$ \\
MWD mm & & $0.42 \pm 22.67^{\mathrm{b}}$ & $0.46 \pm 0.12^{\mathrm{a}}$ \\
\hline
\end{tabular}

* Mean followed by the same letter along the rows not significantly different $(\mathrm{p}>0.05)$ 